\title{
Kawasan Rumah Pangan Lestari pada Panti Asuhan Al-Khairiyah Desa Pematang Berangan, Kabupaten Rokan Hulu, Provinsi Riau
}

\author{
Al Muzafri*1, Nurul Afifah ${ }^{2}$ \\ 1Program Studi Agroteknologi, Universitas Pasir Pengaraian, Indonesia \\ ${ }^{2}$ Program Studi Pendidikan Biologi, Universitas Pasir Pengaraian, Indonesia \\ *e-mail: amuzafri@gmail.com ${ }^{1}$ nurulafifah@upp.ac.id ${ }^{2}$
}

\begin{abstract}
Abstrak
Panti asuhan Al Khairiyah berdiri pada tahun 2010. Panti asuhan Al Khairiyah terletak Desa Pematang Berangan, Kecamatan Rambah, Kabupaten Rokan Hulu, Provinsi Riau. Panti ini berdiri dengan tujuan untuk menampung anak-anak yatim di sekitar Desa Pematang Berangan. Bantuan yang datang umumnya kepada Panti Asuhan Al khairiyah dalam bentuk uang tunai. Bantuan uang tunai kebanyakan digunakan untuk membiayai pendidikan dan sisanya untuk memenuhi sandang pangan. Tidak ada kegiatan khusus yang dilakukan oleh pengurus panti asuhan, baik secara rutin maupun insidental untuk mengasah skill anak-anak yang berada di panti asuhan AL Khairiyah. Program Kawasan Rumah Pangan Lestari (KRPL) merupakan konsep lingkungan yang mengusahakan pekarangan secara intensif untuk dimanfaatkan menjadi sumber pangan secara berkelanjutan. Komoditas yang akan dikembangkan sesuai dengan kebutuhan pangan dan gizi. Tujuan yang diharapkan dari pelaksanaan kegiatan ini adalah Terpenuhinya kebutuhan pangan dan gizi anak-anak asuh melalui optimalisasi pemanfaatan pekarangan secara lestari serta memberikan skill tambahan berupa teknik budidaya buah, sayur dan tanaman obat-obatan yang bisa dimanfaatkan secara langsung oleh warga panti asuhan Al Khairiyah. Pelaksanaan Program KRPL di Panti Asuhan Al khairiyah dimulai dari proses sosialisasi program, Penyemaian Benih dan persiapan lahan, penanaman bibit dan perawatan tanaman. Program KPRL yang dilaksanakan sangat membantu dalam memenuhi kebutuhan pangan di lingkungan Panti asuhan Al-Khairiyah, dengan pengetahuan tentang budidaya beberapa jenis tanaman akan memberikan kesempatan kepada seluruh anak yang ada di panti asuhan Al-Khairyah untuk memenuhi kebutuhan pangan serta belajar dan mempraktekkan budidaya tanaman, khususnya jenis sayur-sayuran.
\end{abstract}

Kata kunci: Pekarangan, Pemanfaatan, Pangan

\begin{abstract}
Al Khairiyah Orphanage was established in 2010. The Al Khairiyah Orphanage is located in Pematang Berangan Village, Rambah District, Rokan Hulu Regency, Riau Province. This orphanage was established with the aim of accommodating orphans around Pematang Berangan Village. The assistance that comes generally to the Al Khairiyah Orphanage is in the form of cash. Most of the cash assistance is used to finance education and the rest to meet food and clothing. There are no special activities carried out by the orphanage management, either routinely or incidentally to hone the skills of the children who are in the $A L$ Khairiyah orphanage. The Kawasan Rumah Pangan Lestari (KRPL) is an environmental concept that intensively cultivates yards to be used as a sustainable food source. Commodities to be developed are in accordance with food and nutritional needs. The expected goal of this activity is to fulfill the food and nutritional needs of foster children through optimizing the sustainable use of the yard and providing additional skills in the form of fruit, vegetable and medicinal plant cultivation techniques that can be used directly by residents of the Al Khairiyah orphanage. The implementation of the KRPL Program at the Al Khairiyah Orphanage started from the program socialization process, seed sowing and land preparation, planting seeds and plant care. The KPRL program implemented is very helpful in meeting food needs in the Al-Khairiyah Orphanage, with knowledge about the cultivation of several types of plants will provide opportunities for all children in the Al-Khairyah orphanage to meet food needs and learn and practice plant cultivation, especially vegetables.
\end{abstract}

Keywords: Food, Utilization, Yard 


\section{PENDAHULUAN}

Program Kawasan Rumah Pangan Lestari (KRPL) merupakan konsep lingkungan yang mengusahakan pekarangan secara intensif untuk dimanfaatkan menjadi sumber pangan secara berkelanjutan dengan mempertimbangkan aspek potensi wilayah dan kebutuhan gizi warga setempat (Purwantini, et al., 2012). Salah satu justifikasi penting dari Program KRPL adalah bahwa ketahanan pangan nasional harus dimulai dari ketahanan pangan di tingkat rumah tangga.

Banyak kajian membuktikan bahwa persediaan pangan yang cukup dalam tingkat wilayah tidak menjamin ketahanan pangan rumah tangga, bukti empiris menunjukkan bahwa di beberapa wilayah di Indonesia masih ditemukan kasus rawan pangan (Ariningsih dan rachman, 2008). Dalam masyarakat perdesaan, pemanfaatan lahan pekarangan untuk ditanami tanaman untuk memenuhi kebutuhan keluarga sudah berlangsung dalam waktu yang lama dan masih berkembang hingga sekarang, biasanya menanam berbagai jenis tanaman untuk dikonsumsi.

Diversifikasi pangan berperanan penting dalam mewujudkan ketahanan pangan, karena kualitas konsumsi pangan dilihat dari indikator skor Pola Pangan Harapan (PPH) nasional masih rendah. Pada tahun 2010 skor PPH baru mencapai 75,7 persen dan harus ditingkatkan terus untuk mencapai sasaran tahun 2014 PPH sebesar 95 persen (Badan Litbang Pertanian, 2011).

Hingga kini pemanfaatan lahan pekarangan di sebagian besar wilayah di Indonesia masih bersifat sambilan, untuk mengisi waktu luang dan ditujukan untuk pemenuhan kebutuhan pangan rumah tangga. Pangan adalah kebutuhan pokok paling dasar bagi kehidupan manusia untuk bertahan hidup maka dari itu ketersediaan pangan menjadi sangat penting terlebih ditengah pertumbuhan penduduk yang saat ini terus meningkat (Tamara, 2020).

Panti asuhan Al Khairiyah berdiri pada tahun 2010. Panti asuhan Al Khairiyah terletak di jalan Kelompok Tani Pasir Putih. Posisi panti berada tepat di belakang pusat pemerintahan daerah Pasir Pengaraian Kabupaten Rokan Hulu. Panti ini berdiri dengan tujuan untuk menampung anak-anak yatim di sekitar kota Pasir Pengaraian.Sejak awal panti ini didirikan, anak-anak yang ditampung tidak hanya anak yatim laki-laki, namun perempuan dan fakir miskin. Kapasitas bangunan yang digunakan untuk mengasuh anak-anak tersebut mampu menampung sekitar 50 orang. Namun, saat ini jumlah anak yang diasuh berjumlah 27 orang dan 7 orang diantaranya adalah laki-laki. Walaupun demikian, gedung laki-laki dan perempuan terpisah.

Anak asuh terdiri dari 9 orang anak sedang mengenyam pendidikan di Sekolah Dasar, 7 orang anak sedang mengenyam pendidikan di Sekolah Menengah Pertama, dan 11 orang anak sedang mengenyam pendidikan di Sekolah Menengah Umum. Semua anak asuh tersebut dibiayai dari beberapa donatur tidak tetap. Pembiayaan saat ini terkendala karena minimnya keuangan panti asuhan, sehingga diperlukan strategi yang tepat supaya semua pendidikan anak asuh dapat terus berjalan dan kebutuhan sandang pangan tercukupi dengan baik. Bantuan yang datang umumnya dalam bentuk uang tunai. Bantuan uang tunai kebanyakan digunakan untuk membiayai pendidikan dan sisanya untuk memenuhi sandang pangan. Sesekali pemenuhan kebutuhan anak-anak asuh terbantu melalui undangan syukuran atau hajatan masyarakat sekitar, buka puasa bersama atau kunjungan instansi tertentu. Tidak ada kegiatan khusus yang dilakukan oleh pengurus panti asuhan, baik secara rutin maupun insidental untuk mengasah skill mereka. Sepulang dari sekolah, hampir semua anak asuh di panti hanya belajar dan mengerjakan tugas sekolah. Sepulang sekolah, banyak diantara mereka yang hanya menghabiskan waktu untuk bermain saja.

Program Kawasan Rumah Pangan Lestari (KRPL) merupakan konsep lingkungan yang mengusahakan pekarangan secara intensif untuk dimanfaatkan menjadi sumber pangan secara berkelanjutan. Komoditas yang akan dikembangkan sesuai dengan kebutuhan pangan dan gizi (Balitbang, 2012). Tujuan yang diharapkan dari pelaksanaan kegiatan ini adalah Terpenuhinya kebutuhan pangan dan gizi anak-anak asuh melalui optimalisasi pemanfaatan pekarangan secara lestari serta memberikan skill tambahan berupa teknik budidaya buah, sayur dan tanaman obat-obatan yang bisa dimanfaatkan secara langsung oleh warga panti asuhan $\mathrm{Al}$ Khairiyah. Pelaksanaan Program KRPL di Panti Asuhan Al khairiyah dimulai dari proses 
sosialisasi program, Penyemaian Benih dan persiapan lahan, penanaman bibit dan perawatan tanaman. Program KPRL yang dilaksanakan sangat membantu dalam memenuhi kebutuhan pangan di lingkungan Panti asuhan Al-Khairiyah, dengan pengetahuan tentang budidaya beberapa jenis tanaman akan memberikan kesempatan kepada seluruh anak yang ada di panti asuhan Al-Khairyah untuk memenuhi kebutuhan pangan serta belajar dan mempraktekkan budidaya tanaman, khususnya jenis sayur-sayuran.

\section{METODE}

Tahapan-tahapan pelaksanaan kegiatan pengabdian ini antara lain:

\subsection{Sosialisasi dan Pelatihan}

Sosialisasi dilakukan oleh tim kepada warga panti asuhan Al Khairiyah dengan melibatkan pemerintah daerah, penyuluh, tokoh masyarakat, untuk menyampaikan maksud dan tujuan pengembangan Kawasan Rumah Pangan Lestari serta membuat perencanaan kegiatan.

\subsection{Penyiapan Lahan dan Media Tanam}

Penyiapan media tanam, kelengkapan vertikultur, sangat menentukan keberhasilan program. Penyiapan media dan wadah tanaman menggunakan bahan baku lokal seperti bambu, wadah dari barang/kemasan bekas pakai, dilakukan oleh warga panti asuhan dengan bimbingan tenaga detasir.

\subsection{Perawatan Tanaman}

Perawatan tanaman secara rutin oleh warga panti asuhan dengan pemberian pupuk kandang, pemasangan ajir untuk penopang tanaman, pemeriksaan dan pengendalian hama/penyakit, dan pemeliharaan ayam/ternak, ikan.

\subsection{Pengembangan kebun Bibit}

Pengembangan kebun bibit merupakan jantung Kawasan Rumah Pangan Lestari, menjadi tempat produksi benih dan bibit untuk panti asuhan Al Khairiyah. Benih/bibit hasil produksi pengembangan kebun bibit juga dijual untuk masyarakat. Kebun Percontohan di Kawasan Rumah Pangan Lestari panti asuhan dibangun untuk tempat pembelajaran anak-anak asuh sekaligus konservasi sumber daya genetik. Kebun Percontohan dibuat menyatu dengan pengembangan kebun bibit atau terpisah untuk tiap komoditas spesifik lokasi.

\section{HASIL DAN PEMBAHASAN}

\subsection{Sosialisasi dan Pelatihan KRPL}

Sosialisasi dilakukan oleh tim kepada warga panti asuhan di kawasan panti dengan melibatkan penanggung jawab panti asuhan, dan penyuluh, untuk menyampaikan maksud dan tujuan pengembangan KRPL serta membuat perencanaan kegiatan. Pelatihan dilaksanakan untuk membekali warga panti asuhan tentang teknologi yang akan diterapkan pada kawasan.
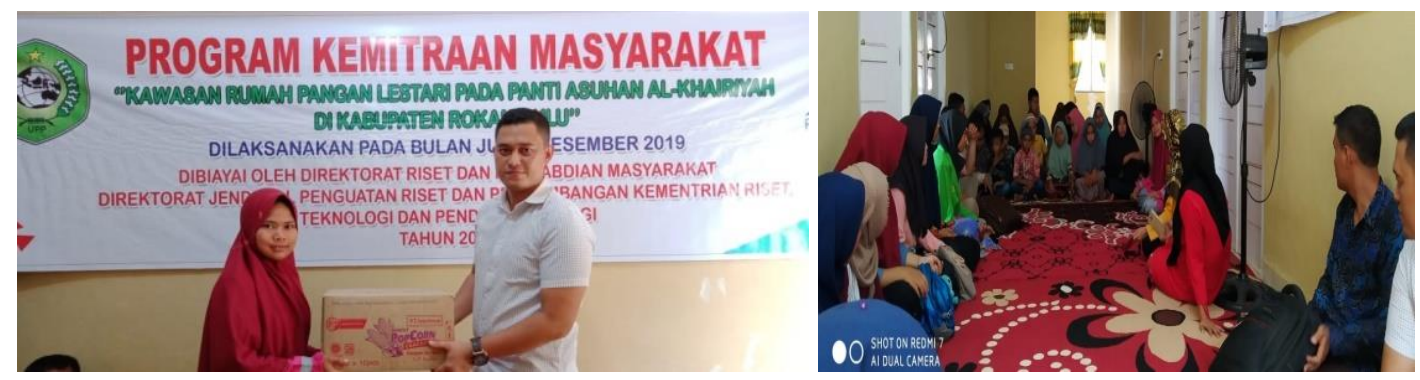

Gambar 1. Sosialisasi dan pelatihan KRPL 


\subsection{Penyemaian benih dan Persiapan lahan}

Penyemaian benih dilakukan di awal proses pembuatan KRPL. Hal ini dimaksudkan agar pada saat lahan telah selesai diolah maka bibit siap untuk ditanam. Penyemaian ini sangat penting, terutama pada benih tanaman yang halus dan tidak tahan terhadap faktor-faktor luar yang dapat menghambat proses pertumbuhan benih menjadi bibit tanaman. Dengan menyemaikan benih terlebih dahulu, diharapkan akan mendapat mutu yang lebih baik, karena dapat dilakukan pemilihan bibit yang cermat dan tepat. Selain itu apabila diusahakan pada lahan yang sempit, maka pemeliharaannya lebih intensif sehingga mengurangi kemungkinan kegagalan atau ketidak tumbuhan bibit. Penyemaian tanaman jenis sayuran dilakukan dengan dua cara yaitu secara langsung yang ditanam pada lahan dan secara tidak langsung atau persemaian. Benih yang disemai secara tidak langsung diantaranya adalah: cabai rawit, kacang panjang, gambas, terong ungu, dan pare. Sedangkan untuk kangkung dan bayam dilakukan teknik penyemaian secara langsung.

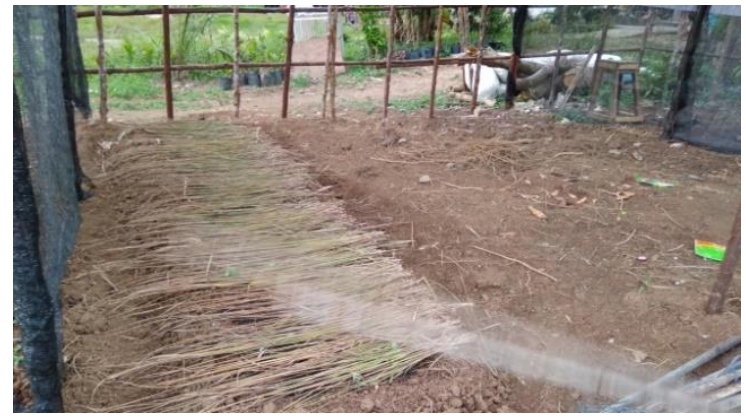

Gambar 2. Penyemaian Benih

Lahan yang diolah untuk pembuatan kawasan rumah pangan lestari berukuran 16 x 28 meter. Lahan kosong yang tersedia cukup luas, namun tidak termanfaatkan dengan baik. Beberapa tanaman yang tumbuh liar di lahan tersebut diantaranya beberapa pohon pisang, ketapang dan jambu dan mangga. Lahan tersebut tidak dimanfaatkan untuk budidaya tanaman pangan dan sayur.

Pengolahan lahan dilakukan dengan menggunakan Jonder yang dioperasikan oleh mahasiswa. Pengolahan lahan ini tidak hanya bertujuan untuk menggemburkan lahan agar mudah ditanami tetapi sekaligus dilakukan pencampuran pupuk kandang sebagai pupuk dasar. Selain itu, dilakukan pembuatan bedengan untuk budidaya beberapa jenis sayuran. Bedengan persegi panjang dibuat $1 \times 10$ meter sebanyak 6 bedengan, 1 buah bedengan modifikasi berbentuk bulat dengan diameter 3 meter, dan 4 bedengan modifikasi berbentuk kubus berukuran $1 \mathrm{~m}^{2}$. Sebanyak 7 bedengan tanpa pembatas batu bata terdapat di bagian bawah lahan. Di sekeliling lahan dipasang pagar yang terbuat dari kayu keras. Selain untuk melindungi tanaman, pagar berfungsi sebagai penopang sayuran yang merambat. Harapannya, sekeliling pagar dapat dimanfaatkan untuk tempat merambatnya sayuran seperti mentimun, gambas, dan tanaman sejenisnya.
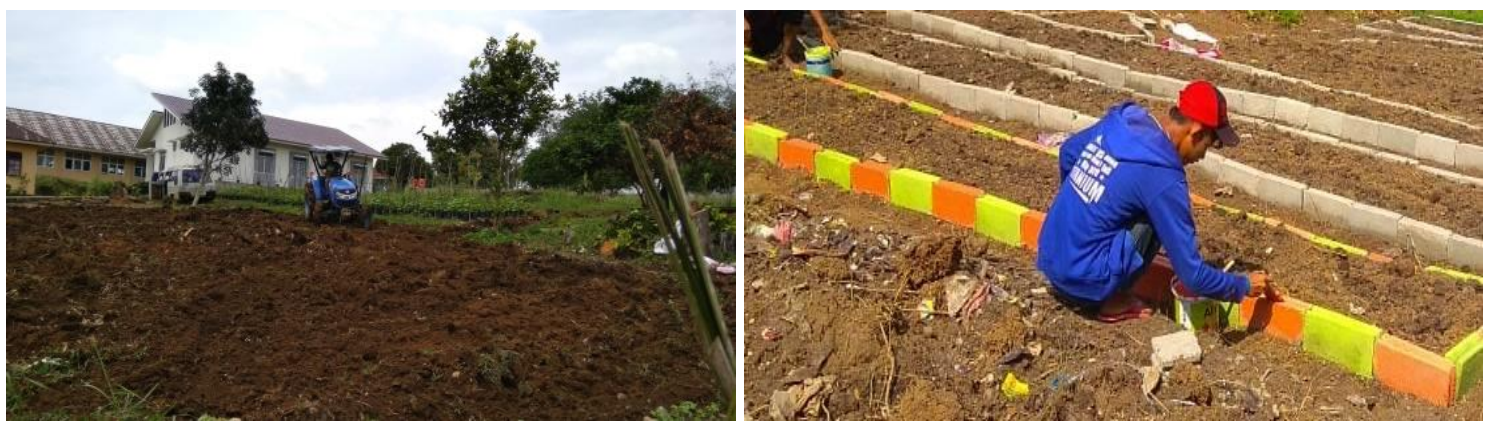

Gambar 3. Pengolahan lahan dan pembuatan bedangan 


\subsection{Penanaman bibit dan perawatan tanaman}

Bibit yang ditanam diambil dari tempat persemaian. Usia bibit yang ditanam sekitar 1 bulan. Bibit yang ditanam diantaranya adalah mentimun, kacang panjang, gambas, terong ungu, pare dan cabai. Selain itu, beberapa bedengan yang berada di bagian bawah lahan ditanami bayam, cabe merah dan kangkung. Bedengan bulat ditanamai beberapa tanaman jahe, jeruk lemon, dan cabe rawit. Bedengan kubus ditanami kunyit, lenguas dan jeruk nipis. Dan untuk bedengan persegi panjang ditanami gambas, mentimun, kacang panjang, terong ungu, cabai rawit, dan pare. Pada beberapa bagian pojok lahan ditanam beberapa pohon lengkeng.

Setiap bedengan persegi panjang berisi 40 tanaman. Selama pembuatan KRPL, bayam dan kangkung sudah bisa dipanen lebih awal dikarenakan tanaman tersebut memiliki umur pendek. Kini, kedua tanaman tersebut sudah bisa dijual dan dinikmati anak-nak panti asuhan sebagai makanan sehari-hari. Adapun tanamn selain itu, baru bisa dipanen setelah 2 bulan masa tanam.

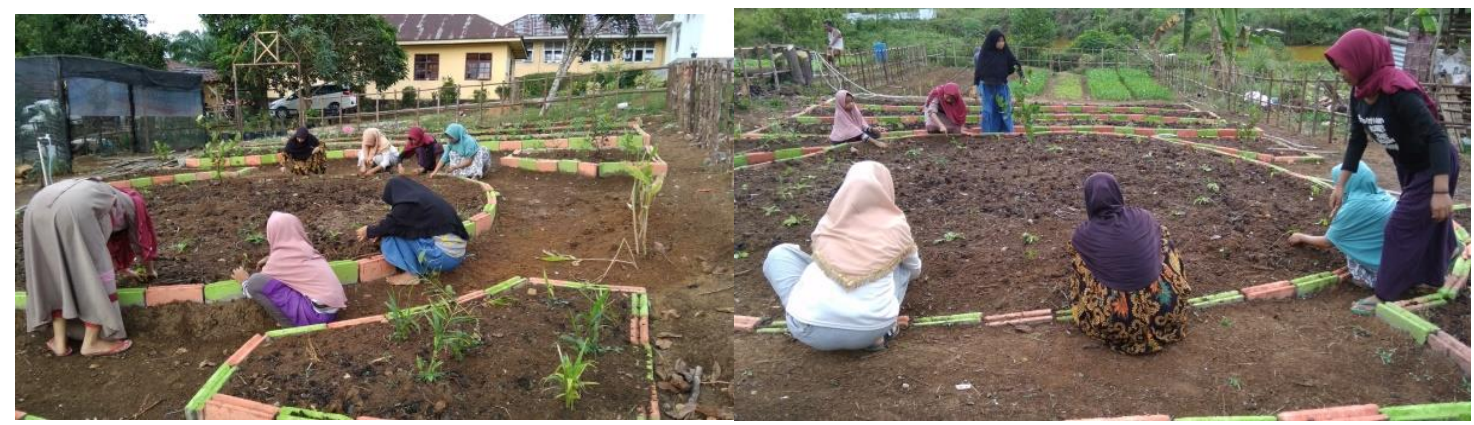

Gambar 4. Penanaman bibit tanaman

Penyiraman tanaman dilakukan setiap hari pada pagi dan sore hari. Jika hari hujan, tidak dilakukan penyiraman. Penyiraman dilakukan dengan menggunakan selang yang terhubung dengan pipa air yang telah dilengkapi dengan pompa air. Untuk penyiraman kangkung dan bayam menggunakan gembor, agar air terdistribusi merata. Pemupukan dilakukan setiap dua pekan sekali menggunakan pupuk NPK mutiara. Beberapa tanaman yang tumbuh merambat akan dipasang ajir. Pemasangan ajir dilakukan setelah tanaman berumur 40 hari. Ajir dibuat dari pelepah sawit yang diambil dari kebun sekitar panti asuhan.

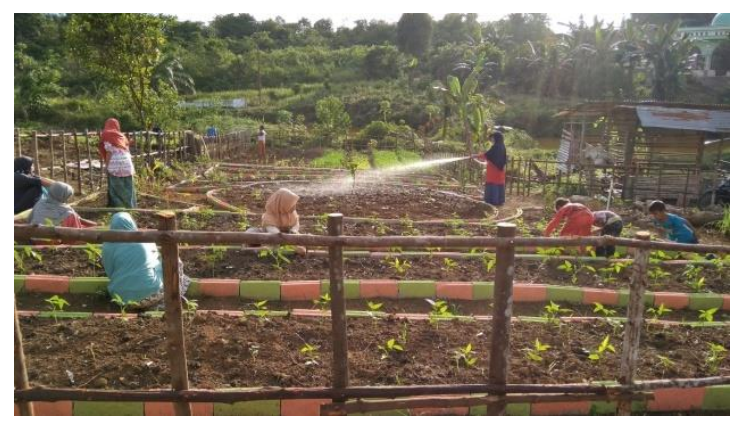

Gambar 5. Perawatan Tanaman

Tahapan kegiatan KRPL yang dilaksanakan pada Panti asuhan Al kahiryah memberikan tambahan pengetahuan bagi anak-anak di panti asuhan tersebut. Pada sebelum program diaksanakan anak-anak yang berada di panti asuhan Al Khairiyah tidak memiliki pengetahuan dalam budidaya tanaman seperti cara persiapan benih dan lahan, penenaman bibit dan perawatan tanaman. Setalah di laksanakan kegiatan pengabdian kepada masyarakat ini memberikan pengetahuan dan skill baru kepada anak-anak panti asuhan dalam bidang budidaya tanaman. 


\section{KESIMPULAN}

Program KPRL yang dilaksanakan sangat membantu dalam memenuhi kebutuhan pangan di lingkungan Pesantren Al-Khairiyah, dengan pengetahuan tentang budidaya beberapa jenis tanaman akan memberikan kesempatan kepada seluruh anak yang ada di panti asuhan $\mathrm{Al}$ Khairyah untuk belajar dan mempraktekkan budidaya tanaman. Anak-anak panti asuhan Al Khairiyah telah memahami teknik budidaya tanaman dimulai dari persiapan benih dan lahan, penenaman bibit dan perawatan tanaman.

\section{DAFTAR PUSTAKA}

Ariningsih, E dan Rachman H.P. (2016). Strategi Peningkatan Ketahanan Pangan Rumah tangga Rawan Pangan. Jurnal Analisis Kebijakan Pertanian Vol 6(3): 239-255. http://ejurnal.litbang.pertanian.go.id/index.php/akp/article/view/4314/3649

Badan Litbang Pertanian. (2011). Pedoman Umum Model Kawasan Rumah Pangan Lestari. Badan Penelitian dan Pengembangan Pertanian. Jakarta.

Balitbang. (2012). Kawasan Rumah Pangan Lestari (KRPL). Jakarta: Balitbang

Kementerian Pertanian. (2011). Pedoman Umum Model Kawasan Rumah Pangan Lestari. Jakarta.

Purwantini T B, Saptana \& Suharyono S (2012). Program Kawasan Rumah Pangan Lestari (Krpl) di Kabupaten Pacitan, Jurnal Analisis Kebijakan Pertanian, Vol 10 (3), 239-256. http://ejurnal.litbang.pertanian.go.id/index.php/akp/article/view/4090/3417

Tamara A, Yusuf M dan Setia B (2020). IMPLEMENTASI PROGRAM KAWASAN RUMAH PANGAN LESTARI (KRPL) DIDESA CIGANJENG KECAMATAN PADA HERANG KABUPATEN PANGANDARAN. Jurnal Agroinfo Galuh, Volume 7(3), 770-776.

https://jurnal.unigal.ac.id/index.php/agroinfogaluh/article/view/4015 